\title{
Desempenho de escolas de ensino médio em territórios vulneráveis
}

*(Universidade Federal de Goiás, Conselho Estadual de Educação de Goiás, Organização das Voluntárias de Goiás, Goiânia, GO)

**(Universidade Federal de Goiás, Goiânia, GO)
Resumo: Este artigo discute os resultados de avaliações externas de 24 escolas estaduais de ensino médio situadas em territórios vulneráveis de três tipos de municípios: regiões metropolitanas, cidades médias e municípios de alta ruralidade. As escolas - dos estados do Ceará, Goiás, Pernambuco e São Paulo - apresentam resultados superiores a outras do mesmo território nas avaliações estaduais e nacionais. 0 objetivo foi compreender como essas escolas e seus atores respondem aos desafios e oportunidades dados pelas condições dos territórios (compreendidos a partir dos tipos de municípios) e pelas políticas educacionais.

Palavras-chave: Territórios vulneráveis. Ensino médio. Desempenho pedagógico. 
Este artigo é parte da pesquisa "Políticas para o ensino médio: o caso de quatro estados", realizada pelo Centro de Estudos e Pesquisas em Educação, Cultura e Ação Comunitária (Cenpec) entre 2015 e 2016. A pesquisa foi realizada junto a escolas públicas de ensino médio situadas em territórios vulneráveis e com indicadores educacionais mais elevados do que outras escolas da mesma rede de ensino situadas no mesmo território. Um dos objetivos do estudo foi compreender o modo pelo qual essas escolas respondem aos desafios e às possibilidades criadas pelas políticas educacionais.

As observações realizadas nas escolas e a análise do discurso dos diversos atores entrevistados sinalizaram que a cultura organizacional das escolas é construída a partir das territorialidades em questão, das relações com o contexto local e das histórias das pessoas envolvidas, criando uma identidade própria que as fazem únicas, mas, ao mesmo tempo, as identificam como parte de um sistema educacional que as homogeneízam ${ }^{1}$. Nessa perspectiva, a compreensão das várias territorialidades em que se encontram as escolas, da clientela juvenil atendida, assim como das particularidades do corpo docente e gestor foi fundamental para o exercício de análise realizado na pesquisa.

Este artigo buscou compreender os resultados das avaliações externas dessas escolas a partir de uma visualização possível de seus territórios e do entendimento das diferentes reações de seus atores (diretores, professores, alunos, famílias e comunidade) ante as políticas educacionais.

Não se trata de comparação entre escolas, mas sim de compreender como em um mesmo território algumas escolas se destacam e tornam-se referência para determinada comunidade. Buscou-se estabelecer diferenças e perguntarse se há nas práticas escolares relações estruturais entre elas (APPLE, 1996² apud BALL; MAINARDES, 2011). Nessa perspectiva, busca-se "reconhecer que diversidade social e diferença são bases importantes para entender 0 escopo das forças sociais ativas envolvidas e resistentes a mudanças" (BALL; MAINARDES, 2011, p.62). Além disso, tenta-se perceber como "os efeitos das políticas são sentidos nos fatores sociais básicos da pobreza, da opressão e da desigualdade" (BALL; MAINARDES, 2011, p.47).

Sobre as potencialidades da cultura organizacional para a compreensão do funcionamento das escolas e suas relações com o sistema de ensino, ver Torres (2005).

APPLE, M. Power, meaning and identity: critical sociology of education in the United States. British Journal of Sociology of Education, v.17, n.2, p. 125-144, 1996. 


\section{TERRITÓRIOS VULNERÁVEIS E VULNERABILIDADE SOCIAL}

Mais do que simplesmente um local geográfico, privilegia-se a compreensão da categoria território em uma perspectiva histórico-cultural. Com isso, procura-se reafirmar as formas subjetivas de representação social que dão identidade ao espaço, priorizando os aspectos simbólicos e visualizando o território como produto da apropriação feita por meio do imaginário e/ou da identidade social sobre o espaço, substrato dos sujeitos que, ao viver, trabalhar, estudar e se divertir, lhe dão significado.

Os territórios são espaços de vida, de relações, construção e desconstrução de vínculos cotidianos, de disputas, contradições e conflitos, de expectativas e de sonhos, que revelam os significados atribuídos pelos diferentes sujeitos (BRASIL, 2008, p. 54).

Dentre os elementos essenciais dessa formulação, destaca-se o território como base de organização do espaço urbano, cujos serviços oferecidos devem obedecer à lógica de proximidade do cidadão. 0 território onde se situa a escola é entendido como espaço de habitação, movimentação, disponibilidade de serviços públicos, locais de trabalho, espaços onde ocorrem relações comunitárias e são construídos laços sociais. Neste artigo, território vulnerável é aquele que padece de equipamentos públicos e de oportunidades culturais, sociais e de trabalho; que apresenta precárias condições de habitação, transporte e elevados índices de violência simbólica e/ou social. Territorialidade são as condições de existência naquele território.

Nas regiões metropolitanas ressalta-se a luta por moradia e a migração urbana e rural, local e/ou regional para centros mais "desenvolvidos", com melhores oportunidades de trabalho como geradores de "novos" espaços de ocupação, seja por meio de invasões, seja por meio de programas de construção habitacional de baixo custo. 0 cidadão tolhido das condições de oportunidade é posto nas porções marginais da cidade, o que expõe sua vulnerabilidade e aumenta as dificuldades de inserção social.

O efeito território no desempenho da escola e dos jovens que nela estudam, assim como a relação estabelecida entre as famílias, os estudantes e a comunidade são questões que vêm permeando vários estudos em educação³. Muitos deles apontam para o fracasso dos alunos, os baixos resultados educacionais e as dificuldades de trabalho de professores e diretores em escolas situadas em territórios vulneráveis. Geralmente a vulnerabilidade econômico-financeira e cultural do local e das famílias que ali residem é

Ver Monteiro (2011), Costa e Lessa (2012), Oliveira e Saraiva (2015), Penna e Ferreira (2014) e Castro e Tavares Júnior (2016). 
considerada um dos grandes responsáveis pelo malogro escolar, assim como pelo abandono ou inadequação das políticas públicas adotadas. Este artigo caminha no sentido inverso. 0 que se pretende é ressaltar o diferencial de algumas escolas e de seus atores, procurando compreender o que as leva a ser mais bem avaliadas em relação a outras escolas em situações semelhantes.

Para isso é preciso considerar a discussão sobre o conceito de vulnerabilidade no campo da análise das políticas sociais.

Castro e Abramovay (2002) discutem a questão da vulnerabilidade:

\begin{abstract}
[...] Parte-se do conceito corrente de debilidades, ou fragilidades, para elaborações que fogem do sentido passivo que sugere tal uso. Na elaboração mais conceitual, vulnerabilidade pede recorrências a diversas unidades de análise - indivíduos, domicílios, comunidades-, além de recomendar que se identifiquem cenários e contextos (Vignoli, 2001; Arraigada, 2001; Filguera, 2001, entre outros). Pede [...] olhares para múltiplos planos, e, em particular, para estruturas sociais vulnerabilizantes ou condicionamentos de vulnerabilidades (CASTRO; ABRAMOVAY, 2002, p. 1).
\end{abstract}

O conceito visto por essa dimensão e por aquela discutida por Katzman (1999) - que aponta a capacidade de indivíduos e grupos sociais enfrentarem e controlarem por meio dos ativos físicos, humanos e sociais as oportunidades propiciadas pelas políticas públicas, pelo mercado ou pela sociedade em seu benefício -, desloca o conceito de vulnerabilidade para, numa compreensão mais dialética, analisar, além das estruturas de exclusão e pobreza, as estruturas de oportunidades, histórica e contextualmente, oferecidas. Existe, assim, o que Castro e Abramovay (2002, p. 146) denominam "vulnerabilidade positiva":

\title{
[...] quando se aprende pelo vivido, a tecer formas de resistências, formas de lidar com os riscos e obstáculos de modo criativo. [...] É quando as vulnerabilidades vividas trazem a semente positiva de um "poder simbólico de subversão".
}

Nessa perspectiva, as políticas públicas de caráter social, dentre elas a educacional, assumem importância histórica e contextual como oportunidades. Conhecer as variadas formas como são implementadas e reelaboradas pelas comunidades escolares, diretores e professores, pais e jovens, no caso das políticas de educação, pode ajudar a compreender como, de um lado, o Estado tem condições de implementar políticas sociais efetivas, não discriminatórias, mais equitativas e, de outro, como os indivíduos, famílias e grupos sociais conseguem, para além de sua situação inicial de vulnerabilidade, driblar as debilidades e fragilidades estruturais e construir perspectivas de transformação e avanços individuais, cooperativos e sociais. 
Na pesquisa e neste artigo, a categoria “vulnerabilidade”,

Em sentido amplo [...] abarca duas condições: a dos "vulnerados", que se identifica à condição de pobreza, quer dizer, que já padecem de uma carência efetiva que implica a impossibilidade presente de sustento e de desenvolvimento, bem como uma debilidade futura, a partir dessa incapacidade; e a dos "vulneráveis", para os quais a deterioração de suas condições de vida não está ainda materializada, mas aparece como uma situação de alta probabilidade em futuro próximo, a partir das condições de fragilidadte que as afete (PERONA; ROCCHI, 2001 apud

Procura-se, neste artigo, compreender como os indivíduos e as escolas utilizam a política educacional como “oportunidades” de superar a situação de vulnerabilidade intrínseca ao território.

\section{TERRITÓRIOS, ESCOLAS E DESEMPENHO}

As quatro regiões metropolitanas 5 observadas detêm o maior número de escolas da amostra (12). Apresentam altos percentuais populacionais em relação aos universos estaduais: Ceará/Fortaleza 34,5\%; Goiás/Goiânia 41,76\%; Pernambuco/Recife 40\% e São Paulo/São Paulo 47,72\%.

A organização dos dados e a análise dos quadros foram embasadas na perspectiva teórico-metodológica de Ball e Mainardes (2011), que orientam para o exercício e a compreensão crítica, ou seja, evitar à primeira vista “qualquer forma de legitimação”. É preciso “levar em conta variações enormes de contexto, de recursos, de desigualdades regionais ou das capacidades locais". Os autores afirmam ainda que "as políticas estão sempre em algum tipo de fluxo, processo de se tornarem algo mais. Esse é, fundamentalmente, o caso da educação que flui ao lado da política (declarações, demandas e expectativas)" (BALL; MAINARDES, 2011, p. 13-14).

No contexto das escolas das regiões metropolitanas delineia-se o seguinte quadro:

4 PERONA, N.; ROCCHI, G. Vulnerabilidad y exclusión social.Una propuesta metodológica para el estúdio de las condiciones de vida de loshogares. Kairós, v. 5, n. 8, 2ํㅗ sem. 2001. Região metropolitana corres ponde a uma porção definida institucionalmente, como, no Brasil, as nove RMs institucionalizadas pela Lei 14 e 20/73 ou as atuais definidas pelas legislações dos estados brasileiros, com finalidade, composição e limites determinados (OBSERVATÓRIO DAS METRÓPOLES, 2009). 
Quadro 1 - Regiões metropolitanas, diversidades sócio espaciais, diversificação da oferta e desempenho das escolas

\begin{tabular}{|c|c|c|c|c|c|c|}
\hline Estados & Municípios & População (2010) & IDHM (2010) & Escolas e oferta diversificada & \multirow{2}{*}{\multicolumn{2}{|c|}{$\begin{array}{c}\text { Avaliação Estadual } \\
\text { (2014) } \\
\text { Spaece }\end{array}$}} \\
\hline \multirow{5}{*}{ Ceará } & & & & & & \\
\hline & & & & & LP & MAT \\
\hline & Município 1 & $2.447,409$ & 0,754 & A- Profissional & 300,4 & 293 \\
\hline & & & & B - Profissional & 299,1 & 312,5 \\
\hline & & & & C-Regular & 247,3 & 240,7 \\
\hline \multirow{5}{*}{ Goiás } & & & & & \multicolumn{2}{|c|}{ Saego } \\
\hline & & & & & $\mathrm{LP}$ & MAT \\
\hline & Município 1 & $1.302,001$ & 0,799 & A-Regular & 269,4 & 264,7 \\
\hline & Município 2 & 455.657 & 0,718 & B - Integral & 305,1 & 307,3 \\
\hline & & & & C-Regular & 256,0 & 255,3 \\
\hline \multirow{4}{*}{$\begin{array}{c}\text { Pernam- } \\
\text { buco }\end{array}$} & & & & & \multicolumn{2}{|c|}{ Saepe (prof.média) } \\
\hline & Município 1 & 644.620 & 0,717 & A - Integral & \multicolumn{2}{|c|}{260,8} \\
\hline & Município 2 & 185.025 & & B - Regular & \multicolumn{2}{|c|}{263,7} \\
\hline & & & & C - Profissional & \multicolumn{2}{|c|}{306,8} \\
\hline \multirow{5}{*}{$\begin{array}{c}\text { São } \\
\text { Paulo }\end{array}$} & & & & & \multicolumn{2}{|c|}{ Saresp } \\
\hline & & & & & $\mathrm{LP}$ & MAT \\
\hline & Município 1 & $11.253,503$ & 0,783 & A-Regular & 303,3 & 298,7 \\
\hline & Município 2 & 666.407 & 0,815 & $\mathrm{~B}$ - Integral & 292,6 & 308,1 \\
\hline & Município 3 & 321.770 & 0,714 & C-Regular & 285,8 & 299,2 \\
\hline
\end{tabular}

Fonte: Elaboração própria.

* O Índice de Desenvolvimento Humano Municipal (IDHM) é uma medida composta de indicadores de três dimensões do desenvolvimento humano: longevidade, educação e renda. 0 índice varia de 0 a 1. Quanto mais próximo de 1, maior o desenvolvimento humano. O IDHM brasileiro segue as mesmas três dimensões do IDH Global longevidade, educação e renda, mas vai além: adequa a metodologia global ao contexto brasileiro e à disponibilidade de indicadores nacionais. Embora meçam os mesmos fenômenos, os indicadores levados em conta no IDHM são mais adequados para avaliar o desenvolvimento dos municípios brasileiros (PNUD, Brasil, 2010).

** Os relatórios de Pernambuco não apresentam dados discriminados de Língua Portuguesa e Matemática. Informam somente a proficiência média dos resultados por escola.

Os dados do Quadro 1 demonstram diferenças demográficas acentuadas entre as capitais e semelhanças entre os IDHMs, que apresentam índices maiores do que o IDH nacional (0,755/2010), com exceção do município do Ceará $(0,754)$, que apresenta diferença mínima. Os índices discrepantes confirmam a dicotomia socioeconômica existente entre a região Sudeste e a região 
Nordeste, apesar de esses municípios apresentarem universos populacionais muito semelhantes. Mais uma vez evidencia-se a desigualdade Nordeste/ Sudeste, chaga histórica da sociedade brasileira. Quanto ao desempenho pedagógico, observa-se que não há nesse aspecto uma correlação direta com os IDHMs.

Os dados mostram ainda que a diversificação na oferta de ensino/matrículas das escolas está associada a desempenhos diferentes. No conjunto dos quatro estados, as escolas de ensino médio regular são as que oferecem três turnos (matutino, vespertino e noturno) e em algumas das quais há classes de ensino fundamental e educação de jovens e adultos (EJA). São também escolas que abrigam maior número de alunos, enfrentam maior "complexidade de gestão"6 e apresentam menores resultados. Na maioria, as escolas de ensino médio regular pesquisadas não atingem a faixa de 300 pontos.

Nos estados do Nordeste são as escolas de ensino profissional em tempo integral que se destacam; em Goiás e São Paulo são as escolas de ensino médio que funcionam em tempo integral. A ampliação de uma política escolar em tempo integral a partir dos anos 2000 está presente em todos os estados pesquisados e sempre apresentando um diferencial de resultados em escala positiva em detrimento dos índices das escolas de ensino regular, nas regiões metropolitanas. Os relatórios evidenciam indicadores "de que as escolas de tempo integral e diurnas possuem melhores condições para assegurar uma educação de qualidade" e menor complexidade de gestão.

A análise dos dados das escolas das regiões metropolitanas possibilitou então a inferência de que

O modelo de política adotado pelos estados pesquisados expressa um esforço de organização dos sistemas educacionais e diversificação da oferta de ensino médio, com semelhanças e diferenças, no que tange à formação docente, currículo, avaliação e monitoramento do ensino e aprendizagem. Entretanto, observa-se que esse esforço pode estar sendo empreendido, na maior parte dos estados, ao custo da garantia da qualidade e da justiça na escola (CENPEC, 2016).

A pesquisa de campo nas escolas identificou alguns elementos que marcam os territórios nos quais estão situadas: más condições de urbanização,

6 O Inep criou um indicador para mensurar o nível de complexidade de gestão das escolas levando em conta as seguintes características: (1) porte da escola (número de matrículas); (2) número de turnos de funcionamento (matutino, vespertino e noturno); (3) complexidade das etapas ofertadas pela escola (crescente com a idade do corpo discente) e (4) número de etapas/modalidades oferecidas. [http//download.inep.gov.br/ informações estatísticas/indicadores educacionais/2014/escola complexidade gestão/ nota técnica indicador escola complexidade gestão.pdf]. 
mobilidades demográficas intensas e efetivação de direitos e cidadania precários, que se processam pari passu com políticas educacionais em implantação, correspondentes ou não à consolidação da equidade e da justiça na escola. No interior das escolas, diretores, professores e alunos relatam como convivem e lidam com as consequências intrínsecas da realidade socioespacial onde vivem. Os territórios das escolas das regiões metropolitanas evidenciam como o espaço de expansão urbana reafirma as diferenças socioeconômicas e culturais.

No Ceará, os pesquisadores observam que,

Ao definir sua rede de escolas de educação profissional, a Secretaria de Educação buscou uma distribuição homogênea no território estadual, situando-as, inclusive, em zonas de maior vulnerabilidade social e econômica. Este é o caso específico das duas escolas profissionais de Fortaleza, ambas localizadas entre os bairros de menor IDH-B, marcados pela pobreza do entorno, onde habitam comunidades com acesso precário a serviços básicos. Esgoto a céu aberto e a falta de pavimentação das ruas apareceu ser lugar comum nas vizinhanças da escola. Vale registrar, no que se refere a este aspecto, que diretores se referiram em suas entrevistas à valorização imobiliária em torno das escolas profissionais [...] (VEIRA; VIDAL, 2016, p. 62).

Em Goiás, diretores detalham características da relação escola/território que vivenciam:

Ela (escola) surgiu debaixo de um pé de mangueira em 1983 [...] esse setor é invasão, ele não é um loteamento, é invasão. Era uma fazenda, [...]. Então, foi onde esse chacareiro montou uma escola, assim, bem precário, nem chegou a ser oficial não, mas foi se tornando oficial. Até hoje o terreno é da prefeitura e o prédio é do Estado [...] (Goiás, diretor de escola de município de grande porte).

O Diretor de Escola de Município da Região Metropolitana descreve o crescimento socioeconômico do bairro, caracteriza o município como "cidadedormitório" e denuncia a falta de lazer.

É uma região mais economicamente sustentável. A gente não tem aqui atividades voltadas para os jovens. A gente não tem nenhum lugar para passear aqui em Aparecida, é uma cidade que tem poucos atrativos. [...] As pessoas dormem aqui, mas tudo que têm para resolver em questão de diversão, principalmente, precisam ir para Goiânia, porque Aparecida não oferece (Goiás, diretor de escola de município de grande porte).

Em Pernambuco, os aspectos marcantes estão na instabilidade da oferta de trabalho e nas desigualdades socioeconômicas das famílias dos alunos. 
A matrícula na escola flutua, muito de acordo com o movimento dos pais dos alunos entre as empresas da região, [...] quando Suape está operando em alta, a gente tem um número maior de alunos, no início do ano mesmo tivemos grande procura de alunos, mas agora em maio, uma firma fechou e nós perdemos quase cem alunos [...] (Pernambuco, diretor de escola de município de grande porte).

Temos uma grande quantidade de alunos que são um pouco desprovidos de recursos, mas também temos alunos que têm condições. Você encontra meninos aqui assim e encontra também aqueles que não têm nada. Só para concluir, tem meninos que vêm aqui só por causa da merenda porque em casa não tem (Pernambuco, professor de escola município de médio porte).

Na fala dos alunos, essa situação é assim descrita:

o pessoal da região eu acho que é mais [rico] do que o da escola. [...] a gente sabe lidar com a questão da desigualdade toda. Isso faz a gente até valorizar mais porque não teve dinheiro

(Pernambuco, aluno de escola de município de médio porte).

\section{Em São Paulo, os pesquisadores ouviram dos diretores que o movimento migratório e as precariedades socioeconômicas são os pontos marcantes:}

Muitas famílias têm "perfil itinerante", o que se deve à dificuldade de fixar residência, [...] perdem o emprego e precisam buscar trabalho em outra região. Um ponto [...] é a 'existência de uma clientela sazonal' [...] oriunda da região nordeste (Pernambuco, Sergipe e Paraíba), o que contribui para um fenômeno peculiar: nos meses de junho e julho, a escola começa a esvaziar porque muitas famílias voltam para seus estados [...] e retornam a São Paulo no final de agosto

(São Paulo, diretor de escola de município de grande porte).

0 quadro dos municípios de médio porte informa discrepâncias menores entre as cidades e os estados em relação ao quadro anterior das regiões metropolitanas. 
Quadro 2- Munícipios de médio porte7, diversidades socioespaciais e desempenho das escolas

\begin{tabular}{|c|c|c|c|c|c|c|}
\hline Estados & Municípios & População (2010) & IDHM (2010) & $\begin{array}{c}\text { Escolas e oferta } \\
\text { diversificada }\end{array}$ & \multirow{2}{*}{\multicolumn{2}{|c|}{$\begin{array}{c}\text { Avaliação } \\
\text { Estadual (2014) } \\
\text { Spaece }\end{array}$}} \\
\hline \multirow{4}{*}{ Ceará } & & & & & & \\
\hline & & & & & LP & MAT \\
\hline & Município 1 & 74.473 & 0,612 & $\begin{array}{c}\text { A - Regular (com } \\
\text { extensões) }\end{array}$ & 300,4 & 327,1 \\
\hline & & & & B - Profissional & 299,1 & 312,5 \\
\hline \multirow{4}{*}{ Goiás } & & & & & \multicolumn{2}{|c|}{ Saego } \\
\hline & & & & & LP & MAT \\
\hline & Município 1 & 182.526 & 0,686 & A - Regular & 274,0 & 265,7 \\
\hline & Município 2 & 69.000 & 0,665 & A - Regular & 272,9 & 264,9 \\
\hline \multirow{3}{*}{ Pernambuco } & & & & & \multicolumn{2}{|c|}{$\begin{array}{l}\text { Saepe } \\
\text { (prof. média) }\end{array}$} \\
\hline & Município 1 & 62.300 & 0,622 & A - Integral & \multicolumn{2}{|c|}{299,4} \\
\hline & & & & B - Profissional & \multicolumn{2}{|c|}{283,4} \\
\hline \multirow{4}{*}{ São Paulo } & & & & & \multicolumn{2}{|c|}{ Saresp } \\
\hline & & & & & LP & MAT \\
\hline & Município 1 & 75.936 & 0,710 & A - Regular & 287,2 & 297,8 \\
\hline & & & & B - Regular & 298,2 & 287,9 \\
\hline
\end{tabular}

Fonte: Cenpec - Pesquisa "Políticas para o ensino médio: o caso de quatro estados”. Relatórios dos Estados, Relatório I (2015), Relatório II (2016).

* Esta escola de ensino médio regular possui cinco anexos ou extensões rurais em povoados e/ ou vilarejos do município. A pesquisa visitou e observou dois dos cinco anexos. Na perspectiva da Secretaria de Educação do Ceará, esses anexos devem ser desativados e seus agentes e alunos transferidos para outra escola-sede construída com a finalidade de abrigar essa clientela.

Os índices apresentam proximidades significativas nos IDHMs e nos resultados pedagógicos. Como explicar IDHMs e resultados de desempenho escolar tão semelhantes em munícipios de porte médio de realidades regionais tão diferentes?

Municípios de médio porte são aqueles em processo de "interações constantes e duradouras tanto com seu espaço regional subordinado, quanto com aglomerações urbanas de hierarquia superior; tamanho demográfico e funcional suficiente para que possam oferecer um leque bastante largo de bens e serviços aos espaços microrregionais a ela ligados; capacidade de receber e fixar os migrantes de cidades menores ou da zona rural, por meio do oferecimento de oportunidades de trabalho, funcionando, assim, como pontos de interrupção do movimento migratório na direção das grandes cidades já saturadas; condições necessárias ao estabelecimento de relações de dinamização com o espaço rural microrregional que o envolve" (AMORIM FILHO; RIGOTTI, 2002 p. 9 apud SILVA, 2013, p. 68). 
Os especialistas no estudo de cidades sugerem que para identificar uma cidade como média é preciso considerar os seguintes critérios: "tamanho demográfico, qualidade das relações externas, especialização e diversificação econômica, posição e sua importância na região e na rede urbana de que faz parte, organização espacial e qualidade de vida" (SOARES, 1999, p. 61 apud SILVA, 2013, p. 67).

Outros autores ainda detalham e explicam:

[...] na busca de identificar e estudar determinada cidade média é preciso analisar o processo de inserção e as constantes re-inserções dessa cidade em sua rede urbana, verificando as interações regionais e, principalmente, as extra-regionais através dos fluxos materiais e imateriais estabelecidos. [...] ter o conhecimento da área de influência dessa cidade em todos os setores, entre eles o político, o de comércio e serviços, o econômico e o de ensino etc. (LEITZKE; FRESCA, $2009^{8}$ p. 7, apud SILVA, 2013, p.66).

As sugestões teóricas auxiliam na análise do quadro, permitindo observar que duas exceções se evidenciam, uma em relação ao número de habitantes, a outra em relação ao IDHM. Acidade de Águas Lindas, no interior de Goiás, pertencente à Ride/DF (Região integrada de desenvolvimento do entorno do Distrito Federal), tem uma população muito superior à dos demais municípios de porte médio relacionados na pesquisa. É considerada uma "cidadedormitório", todo o seu fluxo dirige-se à Brasília e apresenta, no âmbito regional goiano, índice de vulnerabilidade juvenil acima de $70 \%{ }^{9}$. A cidade de Ibiúna, no interior paulista, apresenta IDHM de 0,710, o mais elevado entre os munícipios de porte médio. A hipótese explicativa está no fato de este munícipio apresentar uma vocação para sustentabilidade e preservação ambiental, o que deve propiciar melhor qualidade de vida a seus moradores.

Quanto às semelhanças nos IDHMs, a pesquisa, em razão de seu objeto educacional, apenas identifica a questão e a necessidade de estudos mais aprofundados.

Quanto aos índices de desempenho escolar, as semelhanças são maiores que as diferenças. A maioria (cinco entre oito) é de escolas de ensino médio regular. Os melhores índices em língua portuguesa $(300,4)$ e matemática $(327,1)$ são da Escola A de Município de Médio Porte do Ceará. Essa escola possui cinco anexos em comunidades rurais, o que incitou os pesquisadores a

8 LEITZKE, A.; FRESCA, T. M. Londrina não é cidade média. In: SEMANA DE GEOGRAFIA, 25, SEMINÁRIO DE GEOGRAFIA DO NORTE DO PARANÁ, 4, 2009, Londrina. Anais... Londrina: UEL, 2009. p.1-15.

9 IMB - Instituto Mauro Borges de Estatística e Estudos Socioeconômicos. Mapa dos Índices de Vulnerabilidade Juvenil- 2013. Disponível em: 〈http://www.seplan.go.gov.br/ viewcad.asp?id_cad=4418>. Acesso em: 08 ago. $/ 2015$. 
ampliar a investigação sobre as extensões rurais [...]. A motivação que orientava a visita era captar as impressões dos alunos sobre pertencer a uma escola-sede que se localizava a vários quilômetros de distância e as condições de funcionamento da infraestrutura física que eles utilizavam. [...] Os professores que atuam nos anexos, muitos moradores da própria comunidade, representam baluartes na preservação das extensões rurais nas comunidades, defendem a permanência dos anexos com argumentos que têm suporte nas suas próprias histórias de vida (VEIRA; VIDAL, 2016, p. 62).

Os índices mais baixos estão nas duas cidades goianas, distantes $30 \mathrm{~km}$ uma da outra, ambas incluídas na Ride/DF e com altos índices de vulnerabilidade, como assinalado antes.

Outro aspecto que chama a atenção no quadro das cidades médias é o fato de a política de diversificação da oferta não ser um diferencial no desempenho das escolas. Uma pergunta se coloca: 0 que explica resultados pedagógicos semelhantes em realidades sócio espaciais tão diferentes e em escolas que ofertam modalidades diversas de ensino médio?

Uma hipótese pode ser levantada a partir do que sugere o Observatório das Metrópoles quando discute a mobilização do capital social como facilitador do aproveitamento de oportunidades distribuídas pelo mercado e pelo Estado.

Segundo Kaztmanet alii (1999:268/269) os recursos provenientes da estrutura social [...] são de duas ordens: eficiência normativa que possibilita a existência de expectativas recíprocas, a regulação e controle das condutas que possam colocar em risco de convivência os seus membros, além de incentivar a confiança coletiva; as oportunidades de recursos financeiros e os contatos com o mundo exterior [...]; por último, a composição social [...] atua no sentido positivo pela exposição dos moradores a modelos de ação individual exitosa do ponto de vista integrativo (OBSERVATÓRIO DAS METRÓPOLES, 2005, p. 34).

Nessa perspectiva, os achados da pesquisa sugerem que nos territórios das cidades médias a relação da comunidade com a escola é uma relação de proximidade e integração.

Diretores Escolares assim se expressam:

É uma necessidade para a comunidade ofertar uma escola próxima a sua casa, é uma coisa boa para os pais [...] No que se refere à questão dos conhecimentos,[...] na questão de oportunizar aos alunos outras ferramentas, deixa muito a desejar (Ceará, diretor de escola de município de médio porte). 
Temos uma dificuldade imensa com o ingressante da rede municipal que chega já defasado em nossa escola. Precisamos do primeiro ano todo, para nivelar o conhecimento desse aluno

- ainda mais que no passado oferecíamos o Ensino Fundamental - somente no $2^{\circ}$ ano do EM é que podemos começar a cobrar $100 \%$ desse aluno. Eles chegam de uma realidade sem alfabetização, mal sabem ler e escrever, não respeitam as regras da escola. Mas depois de um ano, incorporam os valores de nossa escola e nos ajudam a construí-la (Goiás, diretor de escola de município de médio porte).

Para algumas comunidades pesquisadas, não importa tanto a modalidade de ensino ofertado pela escola.

Quando digo universalizar, não quero dizer que 100\% das escolas serão em tempo integral. Muitos pais não querem os filhos em uma escola de tempo integral; querem uma escola regular. A gente precisa garantir essa alternativa, mas temos que assegurar a possibilidade que todos os alunos tenham vaga no ensino integral (Pernambuco, secretário de educação do estado).

De forma geral a comunidade tem valorizado mais a escola, principalmente o Ensino Médio. A escola fez a implantação do EJA e muitos pais de alunos voltaram a estudar [...] A educação profissional não existe na região, em relação ao ensino médio de tempo integral, não houve aceitação da comunidade escolar (São Paulo, diretor da escola de município de pequeno porte e de alto índice de ruralidade).

O Quadro 3 indica uma das chagas presentes na relação rural/urbana brasileira: a vulnerabilidade socioeconômica da população de pequenos municípios. Em que pese a inserção dos municípios brasileiros na dinâmica socioeconômica direcionada pela modernidade (relação urbano/rural), precariedades nas condições de vida das comunidades rurais persistem e o risco de reproduzirem uma vulnerabilidade entre seus habitantes continua presente. Os IDHMs desses municípios são os mais baixos, independentemente das diferenças regionais. 
Quadro 3-Munícipios de alta ruralidade, diversidades socioespaciais e desempenho das escolas

\begin{tabular}{|c|c|c|c|c|c|c|}
\hline Estados & Municípios & $\begin{array}{l}\text { População } \\
\text { (2010) }\end{array}$ & IDHM (2010) & $\begin{array}{c}\text { Escolas e oferta } \\
\text { diversificada }\end{array}$ & \multirow{2}{*}{\multicolumn{2}{|c|}{$\begin{array}{c}\text { Avaliação Estadual (2014) } \\
\text { Spaece }\end{array}$}} \\
\hline \multirow{3}{*}{ Ceará } & & & & & & \\
\hline & & & & & LP & MAT \\
\hline & Município 1 & 30.041 & 0,634 & A - Profissional & 290,2 & 307,7 \\
\hline \multirow{3}{*}{ Goiás } & & & & & \multicolumn{2}{|c|}{ Saego } \\
\hline & & & & & LP & MAT \\
\hline & Município 1 & 5.520 & 0,634 & A - Regular & 290,2 & 307,7 \\
\hline \multirow{2}{*}{ Pernambuco } & & & & & \multicolumn{2}{|c|}{ Saepe (prof. média) } \\
\hline & Município 1 & 13.826 & 0,548 & A - Integral & \multicolumn{2}{|c|}{297,8} \\
\hline \multirow{3}{*}{ São Paulo } & & & & & \multicolumn{2}{|c|}{ Saresp } \\
\hline & & & & & LP & MAT \\
\hline & Município 1 & 17.625 & 0,559 & A - Regular e EJA & 284,4 & 296,5 \\
\hline
\end{tabular}

Fonte: Cenpec - Pesquisa "Políticas para o ensino médio: o caso de quatro estados". Relatórios dos Estados, Relatório I (2015), Relatório II (2016).

Os municípios de alta ruralidade pesquisados estão em áreas de assentamento, polos agroindustriais (engenho e usinas de beneficiamento de produtos agrícolas), no caso de Goiás e Pernambuco, e polos turísticos (lazer ecológico e praias marítimas), como é o caso de São Paulo e Ceará. São municípios inseridos na dinâmica do mercado nacional, mas também são comunidades desprovidas de dinamicidade econômica que precisam "saciar suas carências em municípios maiores da proximidade”. Do ponto de vista dos serviços públicos básicos, tornam-se dependentes de outros municípios e muitas vezes resistentes às mudanças. Um exemplo dessa resistência é relatado em entrevista de uma Escola de Município de Pequeno porte e de alto índice de ruralidade do estado de Pernambuco:

Muitos aqui contrariam a vida em casa, tem muitos que até Intercâmbio ${ }_{10}$ ganhou e o pai não permitiu que ele fosse passar seis meses. Então é cultural, o pai não tem informação e não acredita que aquilo direciona a vida do filho [...] acontece dos alunos passarem em vestibular, Educação Física os pais não deixarem [...] Aí às vezes se chama pra conversar, tentar convencer [...] pra mostrar que ele vai ganhar o mundo, ganhar cultura, então a gente tenta fazer esse trabalho com os filhos e com os pais também (Pernambuco, professor de escola de município de pequeno porte e de alto índice de ruralidade).

10 Muitos aqui contrariam a vida em casa, tem muitos que até Intercâmbio ganhou e o pai não permitiu que ele fosse passar seis meses. Então é cultural, o pai não tem informação e não acredita que aquilo direciona a vida do filho [...] acontece dos alunos passarem em vestibular, Educação Física os pais não deixarem [...] Aí às vezes se chama pra conversar, tentar convencer [...] pra mostrar que ele vai ganhar o mundo, ganhar cultura, então a gente tenta fazer esse trabalho com os filhos e com os pais também (Pernambuco, professor de escola de município de pequeno porte e de alto indice de ruralidade). 
A pesquisa evidencia que nesses munícipios, na maioria das vezes, a escola é o único braço de serviço público estadual presente na comunidade. A política educacional é observada e incorporada como direção e orientação a ser seguida e o Estado é presente, seja por meio do monitoramento, seja por meio da relação direta com o órgão superior imediato (diretorias regionais). A gestão escolar é comprometida, o funcionamento cotidiano nos três turnos é regular e há empenho dos agentes educacionais (gestão, professores e alunos) na aprendizagem.

No Ceará, a fala de um diretor de escola de ensino profissional/integral de município de pequeno porte e de alto índice de ruralidade explica como é a gestão escolar e qual é seu envolvimento com a política educacional estadual:

A gente tem uma filosofia de gestão [...]. Uma das premissas é a hierarquia horizontal onde as pessoas seguem não o gestor em si, mas aquela filosofia de gestão e a missão da escola.

Então aqui não há diferença entre funcionários em função do seu nível hierárquico dentro da instituição. Nós temos os professores da base comum, onde eles têm uma relação de extrema harmonia. Os auxiliares de serviços, funcionários, enfim, existe uma harmonia muito importante dentro da escola (Ceará, diretor de escola de município de pequeno porte e de alto indice de ruralidade).

Em Goiás, na escola de Município de Pequeno porte e de alto índice de ruralidade, os pesquisadores também evidenciaram a articulação da escola com a política estadual e a relação da escola com a comunidade. Na escola o que se viu foi uma organização conforme orientações da SEDUCE, um acompanhamento pontual da subsecretaria, por meio do tutor da escola e o empenho e a convicção de que uma boa gestão garante à escola bons resultados. O clima de pertencimento, tanto da equipe gestora quanto de professores e alunos, é outro fator. Para os professores é um status trabalhar no único local do povoado, um emprego de maior qualidade e de nível superior. Para os alunos a escola é a melhor da região; sentem-se eufóricos com a mudança do matutino para o noturno, como se a maturidade se expressasse só pela troca de turno (CENPEC, Goiás, Relatório 1, 2015, p. 112).

Os pesquisadores de Pernambuco evidenciaram com clareza a função social da escola no território:

A escola possui uma forte relação com a comunidade e a cidade, o que se expressa, inclusive, por ser a única escola de Ensino Médio da cidade, além dos poucos aparelhos públicos à disposição. Assim, a escola torna-se um ponto de atividades sociais e culturais para além da educação - como a mediação de conflitos e o uso da quadra para eventos. Além disso, como já apontado, o perfil do aluno de cidade pequena, eminentemente rural é apontado como vantagem. Contudo, há um destaque negativo nessa relação, que é a dificuldade para ultrapassar a perspectiva local (MELLO NETO; MEDEIROS, 2016, p. 55). 


\section{A fala do diretor de uma escola de São Paulo:}

As relações entre os diferentes profissionais da escola são de muita parceria, respeito $e$ comprometimento. Existe muita troca de experiência nesse ambiente, e um trabalho constante de construção de consenso, e também muito desafio de trabalhar em grupo. A equipe atual de professores, coordenadora e a vice também já conhecem bastante a escola e isso facilita o trabalho (São Paulo, diretor de escola de município de pequeno porte e alto índice de ruralidade).

\section{CONSIDERAÇÕES FINAIS}

O estudo realizado indica que as condições de vulnerabilidade dos territórios impactam diretamente as matrículas, a frequência e permanência regular dos alunos e a complexidade da gestão das escolas pesquisadas, que, para garantir o bom funcionamento da instituição (em geral de três turnos) e manter e crescer nos resultados educacionais, precisa minimizar em seu cotidiano pedagógico os efeitos da vulnerabilidade de seu entorno. 0 esforço de minimização da "vulnerabilidade do território" realizado pelas escolas foi principal "achado" da pesquisa.

\section{Para os pesquisadores do Ceará:}

Um aspecto que chamou a atenção se refere a uma certa "sacralização" do espaço da escola na região onde está localizada. Nos bairros da capital, conhecidos pela vulnerabilidade social e violência, a rua na qual se localiza a escola pareceu preservar um clima de normalidade e no depoimento de alguns diretores, a escola é protegida de agressões, invasões e outros tipos de violência, por meio de pactos implícitos ou explícitos com grupos sociais responsáveis por este tipo de violência. (VEIRA; VIDAL, 2016, p. 62-63)

Nos relatórios de Pernambuco, o destaque está no incentivo ao protagonismo do aluno e na relação escola/comunidade. Os pesquisadores apontam que, na compreensão dos atores educacionais, a questão da vulnerabilidade socioeconômica é “ transponível” a partir do envolvimento da comunidade com a escola:

[...] a escola é localizada em um local vulnerável, então no início aquela escola exposta a roubo, a vandalismo, (...) conquistou a comunidade e a comunidade toma conta da escola (Pernambuco, alto cargo de órgão regional).

Na escola, há uma constante tentativa de identificação de pontos e fatores que possam servir de ferramenta de análise aos estudantes e que permitam que o aluno se perceba como agente ativo na comunidade local; que "ele veja o trabalho da Escola naquela comunidade" (Pernambuco, diretor de escola de município de grande porte).

[...] outra coisa que a gente pode colocar aí é o desafio de ter a família dentro da escola, (...) para traçar essa relação de compromisso (Pernambuco, professor de escola de município de grande porte). 
Para os pesquisadores de São Paulo, o mais significativo na pesquisa foi identificar:

O processo de trabalho e o clima de empenho na valorização dos alunos e dos estudos, a noção de pertencimento à escola, o fato de as escolas serem referência para os alunos e um dos poucos espaços comunitários de socialização (GROSBAUM; FALSARELLA, 2016, p. 63).

Já as pesquisadoras de Goiás destacam que a escola é legitimada, tanto pela comunidade interna como pela comunidade externa, é respeitada e, de certa maneira, é um patrimônio daquele grupo social; portanto, ela é resguardada, inclusive, de ameaças externas.

As escolas pesquisadas apresentam um modelo de organização administrativopedagógico legitimado por todos os segmentos escolares (diretores, professores e alunos), pelos pais e pela comunidade. Essas escolas atraem os alunos com melhores recursos familiares, que se adaptam melhor ao "sistema pedagógico" de funcionamento da instituição, dispostos a se submeterem às regras disciplinares e com objetivos mais definidos em relação ao seu futuro profissional. Desse modo, esses estabelecimentos de ensino selecionam, de forma indireta, a clientela que ali ingressa, contribuindo e reforçando a seletividade da rede de ensino e segregando ainda mais, no mesmo território, aqueles jovens mais vulneráveis.

Em síntese, a análise sugere aprofundamento da hipótese de que o processo de construção de equidade e justiça social na escola se fortaleceria muito se as políticas educacionais, em seus arcabouços teórico-empíricos, mesmo sem negar princípios universalistas, se valessem do conhecimento específico já construído sobre a relação escola e territórios vulneráveis aliada à necessidade de abrir canais de diálogo entre as propostas educacionais e a realidade cotidiana das unidades escolares que acumulam experiências no enfrentamento e na superação das dificuldades e desafios que contingencialmente os territórios lhes impõem.

O que a pesquisa mostra é que os esforços de minimização dos efeitos do território no interior das escolas conduzida pelos atores educacionais e pelas famílias no enfrentamento e controle dos "ativos físicos, humanos e sociais", combinados com o desenvolvimento de programas e projetos de políticas educacionais, transformam, criativamente, as condições de vulnerabilidade em oportunidades e em sementes positivas na dinâmica educacional e na construção de espaços escolares de referência nesses territórios. 


\section{Performance of secondary schools in vulnerable areas}

Abstract: This article discusses the results of external assessments for 24 state secondary schools situated in vulnerable areas in three types of municipalities: metropolitan areas, medium cities, and highly rural municipalities. The schools - in the states of Ceará, Goiás, Pernambuco and São Paulo - show higher performance rates than others in the same areas for state and national assessments. Our goal was to understand how these schools and their actors respond to the challenges and opportunities given by the conditions in their areas (considered according with the types of municipality) and by educational policies.

Keywords: Vulnerable areas. Secondary education. Pedagogical performance. 


\section{Desempeño de escuelas de enseñanza media en territorios vulnerables}

Resumen: Este artículo analiza los resultados de las evaluaciones externas de 24 escuelas estatales de enseñanza media brasileñas en territorios vulnerables de tres tipos de municipios: áreas metropolitanas, ciudades medias y municipios de alta ruralidad. Las escuelas - de los estados de Ceará, Goiás, Pernambuco y São Paulo- presentan resultados superiores a otras del mismo territorio en las evaluaciones estatales (provinciales) y nacionales. El objetivo fue comprender cómo estas escuelas y sus actores responden a los desafíos y oportunidades dados por las condiciones de los territorios (comprendidos a partir de los tipos de municipios) y por las políticas educacionales.

Palabras clave: Territorios vulnerables. Enseñanza media. Desempeño pedagógico. 


\section{REFERÊNCIAS}

AMORIM, O, B; RIGOTTI, J. I. R. Os limites demográficos na caracterização nas cidades médias. In: Encontro da Associação Brasileira de Estudos Populacionais, p. 13, 2002. Anais..., Ouro Preto: 2002, p.1-22.

APPLE, M. Power, meaning and identity: critical sociology of education in the United States. British Journal of Sociology of Education, v.17, n.2, p. 125-144, 1996.

BALL, S. J.; MAINARDES, J. (Org.).Políticas educacionais: questões e dilemas. São Paulo: Cortez, 2011.

BATISTA, A. A. G.; CARVALHO-SILVA, H. H. Família, escola, território vulnerável. São Paulo: Cenpec, 2013.

BRASIL. Ministério do Desenvolvimento Social e Combate à Fome. Caderno SUAS Volume 1 - Configurando os eixos da mudança. Brasília: Instituto de Estudos Especiais da Pontifícia Universidade Católica de São Paulo, 2008.

. Ministério do Desenvolvimento Social e Combate à Fome. Norma Operacional Básica da Assistência Social - NOB/SUAS. Brasília, 2005.

CASTRO, M. G.; ABRAMOVAY, M. Jovens em situação de pobreza, vulnerabilidades sociais e violências. Caderno de Pesquisa, São Paulo, n. 116, jul.2002. Disponível em: 〈http://www.scielo.br/scielo.php?script=sci_arttext \&pid=S0100-15742002000200007〉.Acesso em: 22 abr. 2016.

CASTRO, V. G.; TAVARES JÚNIOR, Fernando. Jovens em contextos sociais desfavoráveis e sucesso escolar no ensino médio. Educação \& Realidade, Porto Alegre, v.41, n. 1, p. 239-258, jan./mar.2016.

CENPEC. Pesquisa Ensino Médio, Qualidade e Equidade: avanços e desafios em quatro estados - Ceará, Goiás, Pernambuco e São Paulo. Informe de Pesquisa, n. 11, São Paulo, 2016.

COSTA, R. C.de A. R.; LESSA, S. N. Discutindo a relação entre território e desenvolvimento escolar.Montes Claros: Unimontes, 2012. Disponível em: 〈http://www.unimontes.br/arquivos/2012/geografia_ixerg/eixo_ensino/ discutindo_a_relacao_entre_territorio_e_desenvolvimento_escolar.pdf . Acesso em: 28 abr. 2016.

ÉRNICA, M.; BATISTA, A. A. G. A escola, a metrópole e a vizinhança vulnerável. 
Cadernos de Pesquisa, v. 42, n.146, p.640-666, maio/ago. 2012.

FRESCA, T. M. Em defesa dos estudos das cidades pequenas no ensino de Geografia. Revista Geografia, Londrina, v.10, n.1, p. 27-34, jan./jun. 2001.

GROSBAUM, M. W.; FALSARELLA, A. M. Pesquisa Ensino Médio, Qualidade e Equidade. $2^{\circ}$ Relatório de Pesquisa de São Paulo. São Paulo: Cenpec, 2016, p. 63. [Mimeo].

IMB - Instituto Mauro Borges de Estatística e Estudos Socioeconômicos. Mapa dos Índices de Vulnerabilidade Juvenil- 2013. Disponível em: 〈http:// www.seplan.go.gov.br/viewcad.asp?id_cad=4418>.Acesso em:08 ago. 2015.

KAZTMAN, R. (Coord.) Activos y estrutura de oportunidades. Estudios sobre lasraíces de lavulnerabilidad social em Uruguay. Uruguai: Pnud-Uruguay e Cepal-Oficina de Montevideo, 1999.

LEITZKE, A.; FRESCA, T. M. Londrina não é cidade média. In: SEMANA DE GEOGRAFIA, 25, SEMINÁRIO DE GEOGRAFIA DO NORTE DO PARANÁ, 4, 2009, Londrina. Anais... Londrina: UEL, 2009. p.1-15.

LINDNER, M.; ALVES, F.D.; FERREIRA, E. R. Presença da ruralidade em municípios gaúchos: o exemplo de Silveira Martins, RS. In: XIX ENCONTRO NACIONAL DE GEOGRAFIA AGRÁRIA, p. 1-15, AGRÁRIA/ADG/FFLCH/USP Programa de PósGraduação em Geografia Humana Departamento de Geografia/FFLCH/USP Universidade de São Paulo. Anais... 2009, São Paulo.

MELLO NETO, R. D. M.; MEDEIROS, H. A. Pesquisa Ensino Médio, Qualidade e Equidade. 2ํ Relatório de Pesquisa de Pernambuco. São Paulo: Cenpec, 2016, p. 55. [Mimeo]

MONTEIRO, S.R. da R.O marco conceitual da vulnerabilidade social. Sociedade em Debate, Pelotas, v. 17, n. 2, p. 29-40, jul./dez. 2011.

OBSERVATÓRIO DAS METRÓPOLES. Níveis de integração dos municípios brasileiros em RMs, RIDEs e AUsà dinâmica da metropolização. Rio de Janeiro, 2012. Disponível em: 〈http://www.observatoriodasmetropoles.net/ download/Os_Estados_e_as_RMs_no_Censo_2010.pdf . Acesso em: 18 abr. 2016.

. Os Estados e Regiões Metropolitanas constitutivas do Observatório das Metrópoles no Censo 2010. Rio de Janeiro, mar. 2012. Disponível em: 〈http://www.observatoriodasmetropoles.net/download/Os_Estados_e_as_ 
RMs_no_Censo_2010.pdf〉.Acesso em: 18 abr. 2016.

;IPPUR; FEDERAÇÃO DE ÓRGÃOS PARA ASSISTÊNCIA SOCIAL E EDUCACIONAL. Projeto Análise das regiões metropolitanas do Brasil: relatório da atividade 2 - construção das tipologias. Rio de Janeiro, 2005. Disponível em: 〈https://observatoriogeogoias.iesa.ufg.br/up/215/o/RMG-VF-final2_2_. pdf>. Acesso em: 17 abr. 2016.

OLIVEIRA, D. A.; SARAIVA, A. M.A relação entre educação e pobreza:a ascensão dos territórios educativos vulneráveis. ETD- Educação Temática Digital. Campinas,v.17, n.3, p. 614-632, set./dez.2015.

PENNA, N. A.; FERREIRA, I. B. Desigualdades socioespaciais e áreas de vulnerabilidades nas cidades. Mercator, Fortaleza, v.13, n.3, p. 25-36, set./ dez. 2014.

SOARES, B. R. Repensando as cidades médias brasileiras no contexto da globalização. Revista Formação, Presidente Prudente, v. 1, n. 6, p. 55-63, 1999.

SILVA, A. L.da.Breve discussão sobre o conceito de cidade média. Geoingá: Revista do Programa de Pós-Graduação em Geografia, Maringá, v.5, n.1, p. 58-76, 2013.

TORRES, L. L. Cultura organizacional no contexto escolar: o regresso à escola como desafio na reconstrução de um modelo teórico. Revista Ensaio: Avaliação de Políticas Públicas em Educação, Rio de Janeiro, v. 13, n. 49, p. 435-451, out./dez. 2005.

VEIRA, S. L.; VIDAL, E. M. Pesquisa Ensino Médio, Qualidade e Equidade. 2ํㅡㅁ Relatório de Pesquisa do Ceará. São Paulo: Cenpec, 2016, p. 62. [Mimeo]

\section{Sobre as autoras:}

Eliana Maria França Carneiro é mestre em Educação pelo Instituto de Estudos Avançados em Educação da Fundação Getúlio Vargas do Rio de Janeiro (FGV/ RJ). Professora aposentada da Universidade Federal de Goiás, é conselheira do Conselho Estadual de Educação de Goiás e diretora geral da Organização das Voluntárias de Goiás.

E-mail:franca_eliana@hotmail.com 
Maria Teresa Lousa da Fonseca é doutora em Filosofia e História da Educação pela Pontifícia Universidade Católica de São Paulo (PUC/SP). Professora aposentada da Universidade Federal de Goiás, trabalha como Assessora voluntária de Oscips e ONGs atuantes nas áreas educacional e cultural.

E-mail:mtlousaf@hotmail.com

Recebido em: abril de 2016

Aprovado em: junho de 2016 